\title{
Total Quality Management in Healthcare
}

\author{
Ahmad A. Faloudah, Saber Qasim, Moayd Bahumayd \\ Faculty of Computing and Information Technology, \\ Department of Information Systems \\ King Abdulaziz University, Jeddah, Kingdom of Saudi Arabia
}

\begin{abstract}
Recently, studies have shown that the healthcare sector is witnessing successive variables and the desire of developing require ongoing development and improvement in quality management to accelerate the pace of new developments and management resources optimally in order to improve the quality of service and care to satisfy their customers and responding to their aspirations. The reasons for Total Quality management (TQM) implementation include increased competitive market, high quality healthcare services at practicable costs and advancement of medical technology. It is essential that there be a close correlation between healthcare, which aims to develop new ways to provide services to meet customer needs and total quality management that use the appropriate application to help that sector in order to succeed, where we find that the concept was met with huge success in other management manufacturing and services. This paper describes some of the important affairs of the application of total quality management for the healthcare sector and provides a framework of the application of quality management for them. This framework relies on five measures with a variety of integrated methodology in order to achieve high-quality results. Finally concluded this paper to make it clear that this framework for the application of total quality management contribute to the advancement of trade performance in terms of the health care sector, in addition to raising the levels of conviction among both customers and staff and people as well.
\end{abstract}

Keywords - Total Quality management (TQM); Healthcare;

\section{INTRODUCTION}

Total quality management refers to the management strategy that involves all organizational functions i.e. design sales and marketing, engineering, production, finance, marketing and customer care service with the aim of satisfying customers and achieving the vision and mission of the organization. Total quality management implementation ensures that the employees and management jointly engage in the production of goods and services. The integration of quality management and quality goods and services promotes increase in the organizational opportunities and reduces chances of failure due to minimum utilization of the available resources. Previously total quality management activities were commonly practiced in manufacturing operations but it is now being adopted in the public sector and service organizations. Total quality management involve activities such as: meeting customer needs, involvement of both the employers and employees, teams improvement, reducing the time required for change to have occurred, focus on how to improve the businesses plans, ownership of line management, reduction of products and services costs, just in time flow production, systems to facilitate improvement, challenging the already achieved goals and benchmarking by brainstorming among teams, employee empowerment and active involvement, specific incorporation in strategic planning, recognition and celebration of one's achievements. The above named activities if practiced by all departments in an organization, the business will improve significantly and the customers will be satisfied.

There are many large-scale health-care facilities, which include either a small and relatively simple medical clinics or research and teaching hospitals that are large, complex and expensive.

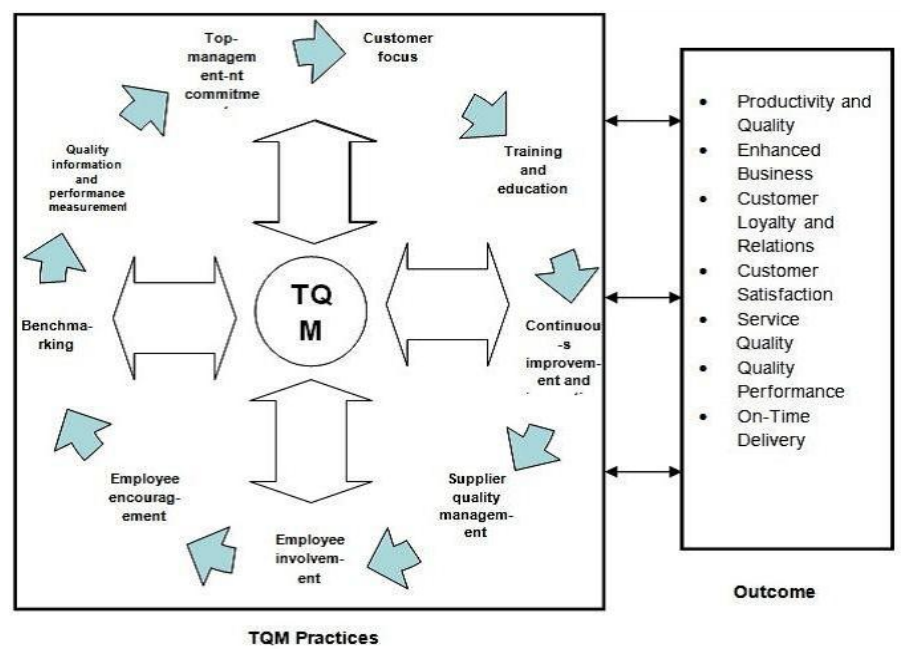

\section{IMPORTANCE OF QUALITY IN HEALTHCARE}

Maintaining high quality standards is very important for health care facilities. The healthcare facilities should appoint an office to be responsible for ensuring quality of care in hospitals, ambulatory surgical treatment centers and nursing homes. The office should license and certify the types of health care facilities available. The office should conduct surveys annually for participation in the Medicare program and should be responsible for investigating all facility complaints received from patients. It is important to maintain quality because if the customers' needs are not satisfied, they may share their opinions and critism through the social networking sites like twitter and Facebook which may damage the organization's reputation and publicity. Accreditation enables the health care to gain new customers by providing confirmation to their prospective customers of the medical facility's ability to provide quality services. 


\section{KEY COMPONENTS OF HIGH QUALITY HEALTHCARE}

Components of a health care system that help provide for high quality health care to patients include: safe systems that cater for all medical conditions of patients. This component goes ahead to show that the safety standards should not be lowered on holidays or at night. Relevant information should only be taken at once by the medical staff and it should be treated with a lot of confidentiality. None of the information shared by a client should be heard from another person except whom it was shared too. A well-organized health care system is associated with efficient and effective health care to its clients. The health care provided depends on the information given which later will determine the kind of health care service, tests and intervention that is appropriate for the client and that which will yield good results .a patient-oriented health care system comprises of : respect to the client's needs, wants and values, teamwork in delivery of care; timely and adequate information, education and communication; physical health; emotional stability; and allowing the friends and family of client to be involved. Quality health care is one that is provided for at the right time. A good health care system should make use of the available resources as much as possible so as to obtain the best value for money thus efficient. Last but not least, a health care system should be non-discriminatory i.e., it should provide equal services to all clients regardless of their race, sex, and social status.

These characteristics of a client are not related to the patients current health status thus should not be criteria for provision of service.

\section{QUALITY IMPROVEMENT}

Improving the capacity to produce good results should be the concern of any health care system. Improved quality system should be a continuous process and it should have a systematic process that needs to be followed so as to improve the health status of clients as well as the services. In health care, quality is achieved when there are desired health outcomes of clients as a result of health care services provided. A successful quality improvement system consists of four key principles: follow the systems and processes; being a team player, patient-focused and focus on use of the data.

Teamwork becomes effective when: there are complexities in the process or system, none of the health staff is aware of the problem, the process is multidisciplinary, the creativity, commitment and acceptance of a solution are needed.

A health care service that is determined to satisfy the needs of patients and their environment includes one that: ensures patients access to the services including providing care after careful examination of the patient, ensures patient is safe or out of danger, ensures the patients pleas are heard, integrates other systems, ensures the language used is appropriate and comfortable for the patient.

On the focus on the data issue, qualitative methods collect data using descriptive characteristics. Qualitative data will be useful in providing information on the improvements that are necessary. It involves checking the observable characteristics of the system which are necessary in determining the relationships and patterns of the various systems involved. Methods that can be used to obtain qualitative data include: surveys, focus group discussions and observations.

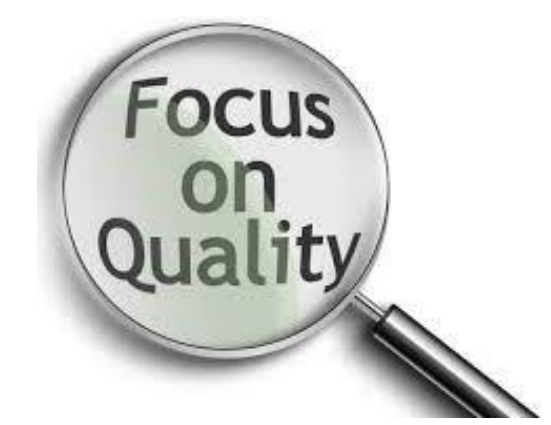

\section{EFFECTS OF IMPROVED QUALITY IN HEALTHCARE SECTOR}

Effects of improved quality in health care facilities include:

Desirable health outcomes of the patients which are accompanied by low health costs incurred. Efficiency of managerial and clinical processes whereby the desired results are obtained by use of as least resources as possible. Improved relationship among staff and non-staff members. This helps identify problems before they actually cause harm by use of early warning systems.

The most important task in management is to determine the management commitment to the goals, policies and plans as shown in the four sides of the total quality management pyramid. Management commitment involves four aspects namely: providing direction through planning, participating in and supporting development, review of company's goals and objectives, and revision of the company's goals. The planning aspect involves analyzing the organization's present situation, vision and setting action plans that will facilitate achieving the set goals. The doing aspect includes participation in the development process, analyzing the strategies of other companies, achieving the best leadership, identifying the best in the specific field and learning the best practices from the best in executing the plans. After doing, check to see if the processes and services are working out well according to the plan. If not review the plan stage and revise the planning stages to achieve better results.

The management must do the following in order to achieve good leadership and good productivity in the health care sector. The top management must: be in agreement on the goals of the company, challenges associated with use of TQM; avoid monotony, appoint someone who can act as link to the top management and also be in charge of quality improvements. Set up an organization that can advise on sustainable improvements throughout the hospitals; inform staff on importance of change and participation in bringing the change, ensure all the staff is involved in a team to ensure the services are well provided. Employee empowerment is achieved through on job training, suggestion scheme, performance and appraisals and excellence teams. Employees should be allowed to make suggestions that will improve the health services offered by the facility. Training should be provided to the employees to increase their knowledge and skills. The employee's performance should be measured periodically and the good performers are recognized so as to motivate them.

The health facilities should use the $8 \mathrm{D}$ problem solving process to solve problems with their services and systems. The steps are as follows: building a team; describing the problem; implementing a temporary fix; identifying and eliminating the root cause; verifying the solution; implementing a more permanent solution; preventing the problem from recurring and finish by celebrating the team success. 
For total quality management implementation to succeed, the health care facilities must make use of these elements namely: ethics, trust, integrity, on job training, leadership, teamwork, communication, and recognition. The elements are divided into four groups depending on their functions. These elements include: either foundation such as integrity, ethics and trust; or building bricks such as leadership and training; or mortar binding such communication; or roof such as recognition. Ethics will determine a business's code of behavior that guides employee's behavior which they are to adhere to when on duty. Honesty, commitment and respect are values that are expected from the staff by the patients. Trust brings about commitment for all members and allows the members to own and commit themselves to the work. Training is very important for medical team as it increases their productivity. Supervisors are solely responsible for implementing and training the employees within their departments about the philosophies of total quality management.

Total quality management requires teamwork which enables the facilities to draw better and permanent resolutions to problems. Total quality management organizations adopt various teams, namely: quality improvement/excellence teams are temporary teams that are given the task of dealing with stubborn problems that tend to be repeated. Problem solving teams which are also temporary identify causes to the problems and also find solutions for the same problems. Natural work teams are skilled and therefore share tasks according to their skills and the use of concepts such as employee involvement teams, self-management teams and quality circles when working. The success of total quality management requires communication within all the health care departments, members, patients and suppliers. Supervisors must maintain freedom of disseminating and obtaining any information about the TQM processes. TQM should provide knowledge about the overall quality of the proposals and achievements of management teams as well as individuals as it boosts their self-esteem, motivation and confidence.

Total quality management implementation enables the health facilities to maximize patients' satisfaction, achieve higher productivity and gain better service quality. TQM helps reduce waste. TQM provides a continuous improvement of quality services and the employees of the facility. TQM implementation maintains strong relationship with the individuals through achievement of providing high quality services that ensures customer satisfaction.

TQM works by using measurement tools. In healthcare setting, excellence is measured in health outcomes and the patients' satisfaction. There are five concepts seen in the study of TQM in healthcare settings. A focus on customers as the healthcare focuses on the patient's recovery. Continuous improvement and learning. The healthcare facilities ensure that they improve their services and accessibility to medicine in the hospitals and pharmacies. The hospitals usually recruit the best candidates. The healthcare personnel are usually taken for training after a set period to refresh their knowledge and skills. The quality of training program is reflected on the quality of graduates. Some attend conferences where they are further trained on quality healthcare. All employees work together as a team since all steps or stages of receiving treatment are interconnected. The top managers work with employees to foster mutual commitment to TQM elements which help the organization excel i.e. getting the independent physicians to commit fulltime to the hospital's TQM goals. The various team's i.e. first aiders, nurses, doctors and surgeons work together as a team to ensure patients receive quality care and recover well. A commitment by top management. The management ensures that all the set goals are met and that the required resources are available like the $\mathrm{x}$-ray and laboratory equipment.

The management should encourage employee learning and empowerment. The management should motivate the workers, recognize the effort of the achievers and give them incentives.

A process approach to the organization's business challenges which refers to seeing the organizational functions as a series of interconnected steps and procedures each of which can be improved individually.

\section{CONCLUSION}

There are basic elements that ensure the success of TQM in the organization. An overseer is the key in ensuring these elements are applied in the organization. The business entities cannot be successful TQM implementers without the above mentioned elements. Leadership and teamwork are interconnected. Lack of a link between the departments in an organization, supervisors, managers and employees create a challenge to the TQM implementation process. Members of an organization who have contributed to its success should be recognized or awarded. Health care facilities should train employees on how to offer quality services and also provide a conducive environment that supports sharing of skills and knowledge and give credit where its due to achieve a successful TQM.

\section{REFERENCES}

[1] Martin, L. (1993). "Total Quality Management in the Public Sector," National Productivity Review, 10, 195 213

[2] Carman, James M.; Shortell, Stephen M.; Foster, Richard W.; Hughes, Edward F.X.; Boerstler, Heidi; O' Brien, James L.; O'Connor, Edward J, January 01, 2010). Keys for Successful Implementation of Total Quality Management in Hospitals.

[3] Oakland, J. S. (1989). "Total quality management. Oxford: Heinemann professional pub".

[4] Diego Prior (2006) "Efficiency and total quality management in health care organizations: A dynamic frontier approach". Springer Science, Business Media, LLC 2006.

[5] Faisal Talib, Zillur Rahman, Mohammed Azam (2010). "Total Quality Management Implementation in the Healthcare Industry: A Proposed Framework". 2nd International Conference on Production and Industrial Engineering CPIE-2010 http://www.academia.edu/228453/Total_Quality_Mana gement_Implementation_in_the_Healthcare_Industry_ A_Proposed_Framework 